\title{
Protective Effect of Green Perilla-Derived Chalcone Derivative DDC on Amyloid $\beta$ Protein-Induced Neurotoxicity in Primary Cortical Neurons
}

\author{
Mami Iwasaki, ${ }^{a}$ Naotaka Izuo, ${ }^{a}$ Yasuhiko Izumi, ${ }^{a, b}$ Yuki Takada-Takatori, ${ }^{c}$ Akinori Akaike,,${ }^{a, d}$ and \\ Toshiaki Kume*,a,e \\ ${ }^{a}$ Department of Pharmacology, Graduate School of Pharmaceutical Sciences, Kyoto University; 46-29 \\ Yoshidashimoadachi-cho, Sakyo-ku, Kyoto 606-8501, Japan: ${ }^{b}$ Laboratory of Pharmacology, Kobe Pharmaceutical \\ University; 4-19-1 Motoyamakita-machi, Higashinada-ku, Kobe 658-8558, Japan: ${ }^{c}$ Department of Rational \\ Medicinal Science, Faculty of Pharmaceutical Sciences, Doshisha Women's College; Kodo, Kyotanabe, Kyoto \\ 610-0395, Japan: ${ }^{d}$ Wakayama Medical University; 811-1 Kiidera, Wakayama 641-0012, Japan: and ${ }^{e}$ Department \\ of Applied Pharmacology, Graduate School of Medical and Pharmaceutical Sciences, University of Toyama; 2630 \\ Sugitani, Toyama 930-0194, Japan.
}

Received August 5, 2019; accepted August 8, 2019; advance publication released online August 29, 2019

Amyloid $\beta$ protein (A $\beta$ ) causes neurotoxicity and cognitive impairment in Alzheimer's disease (AD). Oxidative stress is closely related to the pathogenesis of AD. We have previously reported that $2^{\prime}, 3^{\prime}$-dihydroxy-4',6'-dimethoxychalcone (DDC), a component of green perilla, enhances cellular resistance to oxidative damage through the activation of the nuclear factor erythroid 2-related factor 2 (Nrf2)-antioxidant response element (ARE) pathway. Here, we investigated the effects of DDC on cortical neuronal death induced by $A \beta$. When $A \beta$ and DDC had been preincubated for $3 \mathrm{~h}$, the aggregation of $A \beta$ was significantly suppressed. In this condition, we found that DDC provided a neuroprotective action on $A \beta$-induced cytotoxicity. Treatment with DDC for $24 \mathrm{~h}$ increased the expression of heme oxygenase-1 (HO-1), and this was controlled by the activation of the Nrf2-ARE pathway. However, DDC did not affect A $\beta$-induced neuronal death under any of these conditions. These results suggest that DDC prevents the aggregation of $A \beta$ and inhibits neuronal death induced by $A \beta$, and although it activates the Nrf2-ARE pathway, this mechanism is less involved its neuroprotective effect.

Key words amyloid $\beta$ protein; aggregation; neurotoxicity; nucleus erythroid p45-related factor-2-antioxidant response element pathway

\section{INTRODUCTION}

Alzheimer's disease (AD) is a progressive neurodegenerative disease in which main symptom is the impairment in cognitive functions such as memory and learning, and where neuronal loss in the cerebral cortex and hippocampus is observed. ${ }^{1)}$ One of the major pathological findings in $\mathrm{AD}$ is the presence of senile plaques in the brain composed mainly of amyloid $\beta$ protein $(\mathrm{A} \beta)$ that induce neuronal cell death. ${ }^{2)}$ Therefore, it has been suggested that $\mathrm{A} \beta$ plays an important role in the extensive neuronal loss seen in $\mathrm{AD}$, and it is considered that suppressing $\mathrm{A} \beta$-induced neurotoxicity leads to a fundamental treatment of AD.

We have previously reported that in cultured cerebral cortex neurons, the mechanism of $\mathrm{A} \beta$-induced neuronal cell death occurs through aggregation of $\mathrm{A} \beta$ and the subsequent increase in intracellular oxidative stress. ${ }^{3)}$ Flavonoids containing a catechol group have been reported to inhibit the aggregation of $\mathrm{A} \beta{ }^{4}$.

The intracellular nuclear erythroid 2-related factor 2 (Nrf2)-antioxidant response element (ARE) pathway plays an important role in the defense mechanism against oxidative stress. We searched for food-derived components that activate the Nrf2-ARE pathway and isolated 2',3'-dihydroxy-4',6'dimethoxychalcone (DDC) from its ether extract. We previously reported that DDC has a cytoprotective activity against 6-hydroxydopamine-induced oxidative stress in $\mathrm{PC} 12$ cells. ${ }^{5)}$ DDC contains a catechol structure with aggregation inhibi- tory activity and exhibits oxidative stress inhibitory activity through the activation Nrf2-ARE pathway.

In this study we examined the effect of DDC on $\mathrm{A} \beta$ induced neurotoxicity using primary cortical neurons and further analyzed the mechanism of action by focusing on the aggregation of $\mathrm{A} \beta$ and oxidative stress.

\section{MATERIALS AND METHODS}

Cell Culture Cerebral cortex was isolated from embryonic 17-19-d-old Wistar/ST rat fetuses, and cells were seeded on a plate/dish coated with $0.1 \%$ polyethylenimine. The cells were cultured at $37^{\circ} \mathrm{C}$ and $5 \% \mathrm{CO}_{2}$ in Neurobasal medium containing penicillin-streptomycin and 2\% B27 supplement. After $4 \mathrm{~d}$, the cells were cultured in L-glutamate-free medium. At the time of drug treatment, media containing B27 supplement without 5 antioxidants (vitamin E, vitamin $\mathrm{E}$ acetate, superoxide dismutase, catalase, and glutathione) was used. Animals were treated in accordance with the guidelines of the Kyoto University Animal Experimentation Committee and the guidelines of The Japanese Pharmacological Society.

Synthesis and Purification of $\mathbf{A} \boldsymbol{\beta} \quad \mathrm{A} \beta$ was synthesized by Fmoc solid phase synthesis using a peptide synthesizer (Pioneer, Life Technologies, U.S.A.). Synthesis started from the $\mathrm{C}$-terminus and the full length of $\mathrm{A} \beta$ was synthesized by repeating the Fmoc-amino acid coupling reaction and the Fmoc group deprotection reaction. Purification of the crude peptide was performed using a reverse phase HPLC system. The con- 
ditions used were: $0 \mathrm{~min} \mathrm{H}_{2} \mathrm{O} / \mathrm{CH}_{3} \mathrm{CN} / \mathrm{NH}_{4} \mathrm{OH}(90 / 10 / 0.1) \rightarrow$ $80 \mathrm{~min}_{2} \mathrm{O} / \mathrm{CH}_{3} \mathrm{CN} / \mathrm{NH}_{4} \mathrm{OH}(50 / 50 / 0.1)$ and showed the largest peak appearing at $25-35 \mathrm{~min}$ retention time. Fractions were then collected. A Develosil column (Nomura Chemical Co., Aichi, Japan) was used for this purpose.

Evaluation of Neuronal Cell Death Cells were cultured for $9-10 \mathrm{~d}$ before being used for testing. Neuronal cell death was assessed using the 3-(4,5-dimethylthiazol-2-yl)-2,5-diphenyl-tetrazolium (MTT) assay. The survival rate for each drug treatment group was calculated as a percentage compared to the survival rate in the solvent treatment group.

Evaluation of $\boldsymbol{\beta}$-Sheet Structure Formation Beta sheet structure formation was evaluated using the Thioflavin $\mathrm{T}$ (ThT) assay. A $\beta$ was added to the Neurobasal media and incubated at $37^{\circ} \mathrm{C}$. Samples for measurement were then collected at $0,4,8$, and $24 \mathrm{~h}$. Glycine- $\mathrm{NaOH}$ buffer ( $\mathrm{pH} 8.5$ ) containing ThT at $5 \mu \mathrm{M}$ was added at $100 \times$ the amount of the sample for measurement and fluorescence intensity was calculated $(\mathrm{Ex} / \mathrm{Em}=420 \mathrm{~nm} / 485 \mathrm{~nm})$. The value for each treatment group was calculated as a percentage using the fluorescence intensity of the $\mathrm{A} \beta(20 \mu \mathrm{M})$-containing solution after $24 \mathrm{~h}$.

Western Blot Cell lysates from the cultured cells treated with DDC was obtained by lysis buffer $(20 \mathrm{mM}$ Tris, $25 \mathrm{mM}$ $\beta$-glycerophosphate, $2 \mathrm{mM}$ ethylene glycol-bis $(\beta$-aminoethyl ether)- $N, N, N, N^{\prime}$-tetraacetic acid, $1 \%$ Triton $\mathrm{X}-100,1 \mathrm{mM}$ phenylmethylsulfonyl fluoride, $1 \%$ aprotinin, $2 \mathrm{mM}$ dithiothreitol, and $1 \mathrm{mM}$ vanadate). The amount of protein was normalized for each sample before sodium dodecyl sulfatepolyacrylamide gel electrophoresis (SDS-PAGE) was performed. Proteins were separated by SDS-PAGE, transferred to a polyvinylidene difluoride (PVDF) membrane (Millipore, Bedford, MA, U.S.A.), incubated with anti-heme oxygenase-1 (HO-1) antibody (Code \#ADI-SPA-895) purchased from Enzo Biochem Inc. (Stressgen, Victoria, Canada) and secondary antibody (anti-rabbit immunoglobulin G [IgG] horseradish peroxidase-linked whole antibody and detected by an enhanced chemiluminescence detection system (GE Healthcare). Band intensities were measured using the ImageJ software (National Institutes for Health, Bethesda, Maryland, U.S.A.).

Statistical Analysis All data are expressed as mean \pm standard error. Statistically significant differences were evaluated using a Student's $t$-test or a one-way ANOVA with post-hoc Tukey's test. Statistical significance was inferred when the risk factor was lower than $5 \%$.

\section{RESULTS}

Inhibitory Effect of DDC on the Aggregation of A $\boldsymbol{\beta}$ We first examined the effect of DDC on the aggregation of $\mathrm{A} \beta$. The incubation of $\mathrm{A} \beta$ in media at $37^{\circ} \mathrm{C}$ increased the ThT fluorescence in a time-dependent manner over 4-24h (Fig. 1A). Incubation of cells with $\mathrm{DDC}$ and $\mathrm{A} \beta$ simultaneously did not affect the aggregation of $\mathrm{A} \beta$ (Fig. 1A). On the other hand, when ThT fluorescence was measured under the conditions where $\mathrm{A} \beta$ and $\mathrm{DDC}$ had been preincubated at $37^{\circ} \mathrm{C}$ for $3 \mathrm{~h}$ prior to addition to the cell media, then the aggregation of A $\beta$ was significantly suppressed at 8 and $24 \mathrm{~h}$ after the start of pre-incubation (Fig. 1B).

Protective Effect of DDC on A $\beta$-Induced Neurotoxicity We then examined the effect of DDC on $\mathrm{A} \beta$-induced neurotoxicity in cortical neuronal cells. Under the cells' incubation conditions which did not show an inhibitory effect against the aggregation of $\mathrm{A} \beta$ and DDC as shown in Fig. 1A, DDC showed no protection against $\mathrm{A} \beta$-induced neurotoxicity (Fig. $2 \mathrm{~A})$. On the other hand, under the conditions which $\mathrm{A} \beta$ and DDC were preincubated for $3 \mathrm{~h}$, DDC exhibited a protective effect against $\mathrm{A} \beta$-induced neurotoxicity in a concentration dependent manner (Fig. 2B).

Influence of Oxidizing and Reducing Agents on the DDC Inhibitory Effect of the Aggregation of $\mathbf{A} \boldsymbol{\beta}$ It has been previously suggested that the formation of an oxidized form (o-quinone form) of the catechol site by air oxidation is an important step for suppressing the aggregation of $\mathrm{A} \beta$ by flavonoids containing a catechol group. ${ }^{4}$ Therefore, we analyzed the effects of an oxidizing and reducing agent on the aggregation suppressing action of DDC. When the oxidizing agent sodium periodate $\left(\mathrm{NaIO}_{4}\right)$ was added to the culture media, the aggregation suppressing effect of DDC was significantly enhanced at $24 \mathrm{~h}$ (Fig. 3A). On the other hand, when the reducing agent tris(2-carboxyethyl)phosphine (TCEP) was added to the culture media, the aggregation inhibitory action by DDC was significantly suppressed after an $8 \mathrm{~h}$ incubation, and this suppression trend was observed up to $24 \mathrm{~h}$ (Fig. 3B).

Influence of Oxidizing and Reducing Agents on the
A
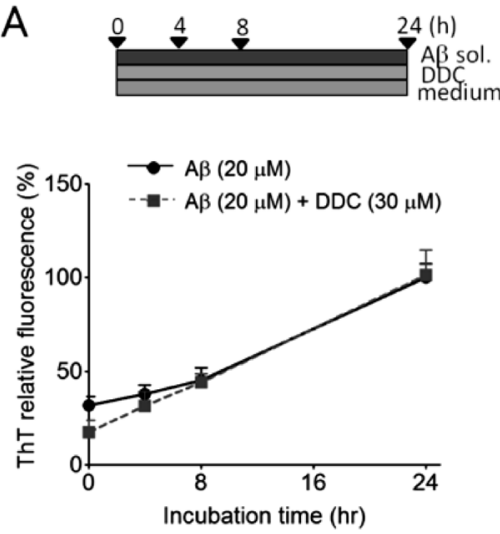

B

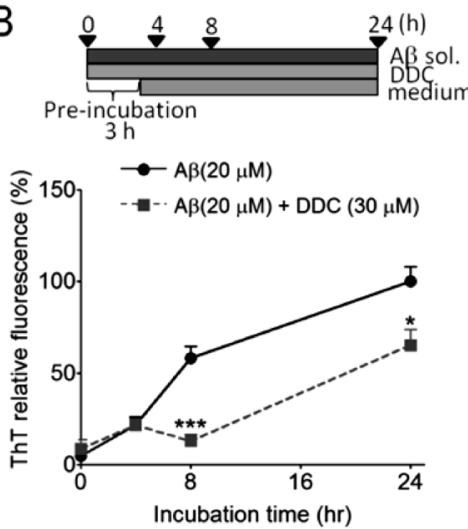

Fig. 1. Effect of Pre-incubation of DDC with $\mathrm{A} \beta$ on the Aggregation of $\mathrm{A} \beta$

A: The aggregation of $\mathrm{A} \beta(20 \mu \mathrm{M})$ was assessed using ThT assay in Neurobasal media in the presence or absence of DDC $(30 \mu \mathrm{M})$ at $37^{\circ} \mathrm{C}$. B: $\mathrm{A} \beta(200 \mu \mathrm{M})$ was preincubated for $3 \mathrm{~h}$ in the presence or absence of DDC $(300 \mu \mathrm{M})$ at $37^{\circ} \mathrm{C}$ and then was added to Neurobasal media. The aggregation of $\mathrm{A} \beta$ was assessed using ThT assay. $* p<0.05, * * * p<0.001$, compared with $\mathrm{A} \beta$. 
A

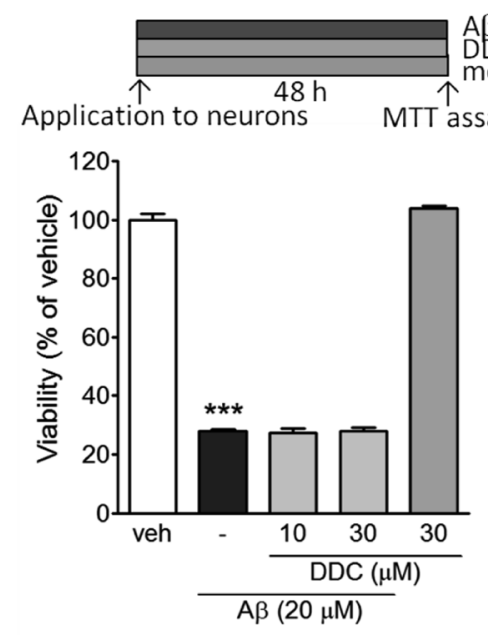

B Pre-incubation
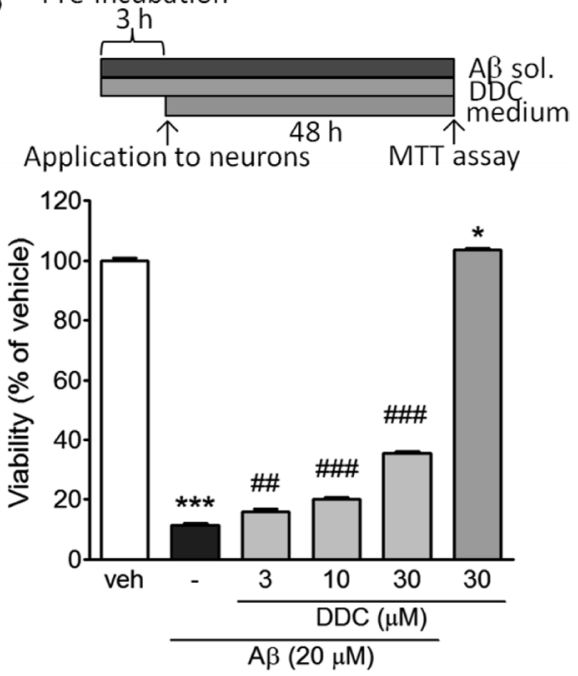

Fig. 2. Effect of DDC on $\mathrm{A} \beta$-Induced Neurotoxicity

A: Cells were treated with DDC and $\mathrm{A} \beta$ simultaneously for $48 \mathrm{~h} . \mathrm{B}$ : $\mathrm{A} \beta$ was preincubated for $3 \mathrm{~h}$ in the presence or absence of $\mathrm{DDC}$ at $37^{\circ} \mathrm{C}$ (pre-incubation), and then added to Neurobasal medium. Cultures were treated for $48 \mathrm{~h}$ with preincubated DDC $+\mathrm{A} \beta$ media. $* p<0.05, * * * p<0.001$, compared with vehicle (veh). ${ }^{\# \#} p<0.01$, $\# p<0.001$, compared with $\mathrm{A} \beta$.
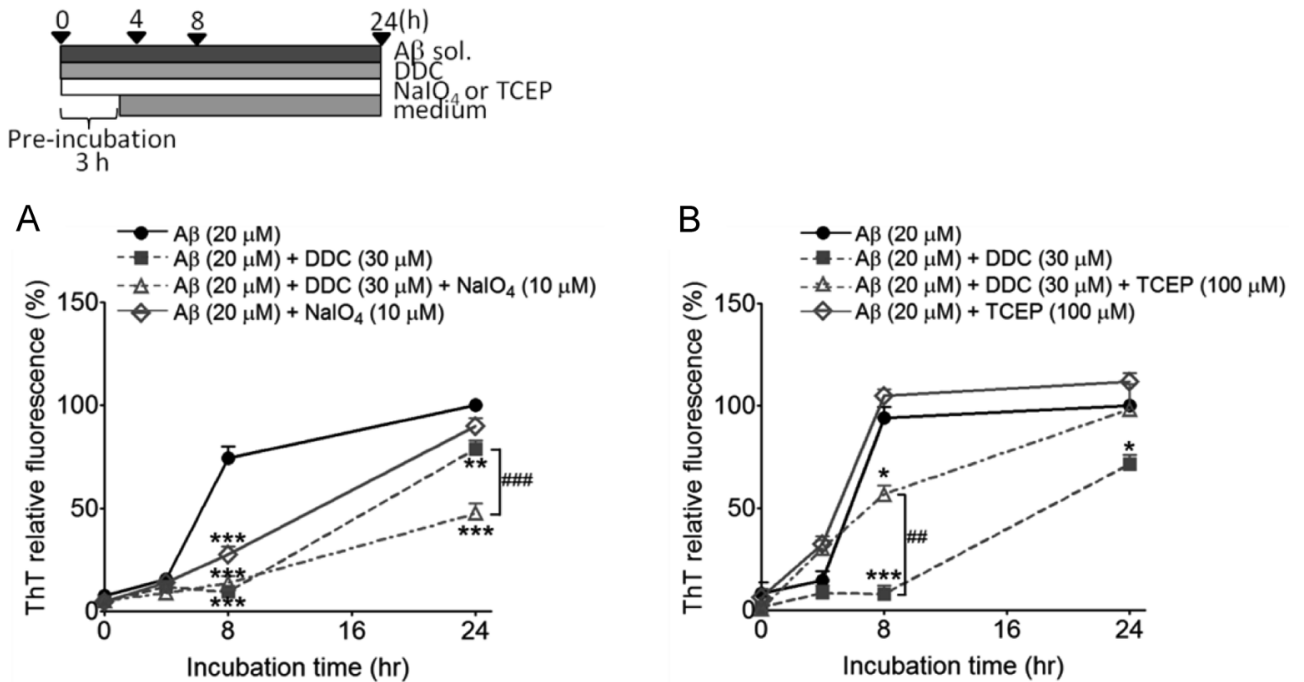

Fig. 3. Effects of $\mathrm{NaIO}_{4}$ or TCEP on DDC Ability to Inhibit A $\beta$ Aggregation

$\mathrm{A}, \mathrm{B}: \mathrm{A} \beta(20 \mu \mathrm{M})$ was preincubated for $3 \mathrm{~h}$ in the presence or absence of DDC $(30 \mu \mathrm{M})$ or $\mathrm{NaIO}_{4}(10 \mu \mathrm{M})(\mathrm{A})$, or TCEP $(100 \mu \mathrm{M})(\mathrm{B})$ at $37^{\circ} \mathrm{C}($ pre-incubation), and then added to Neurobasal medium. The aggregation of $\mathrm{A} \beta$ was assessed using the ThT assay. ${ }^{*} p<0.05$, $* * p<0.01,{ }^{* * *} p<0.001$, compared with $\mathrm{A} \beta,{ }^{\# \#} p<0.01,{ }^{\# \#} p<0.001$.

Neuroprotective Action of DDC We investigated the effect of $\mathrm{NaIO}_{4}$ or TCEP on the protective property of DDC on $\mathrm{A} \beta$ induced neurotoxicity. When $\mathrm{A} \beta$ was pre-incubated with DDC and $\mathrm{NaIO}_{4}$ for $3 \mathrm{~h}$ and then added to the culture media, the protective effect of DDC against $\mathrm{A} \beta$-meditated toxicity was significantly enhanced by the addition of $\mathrm{NaIO}_{4}$ (Fig. 4A). In contrast, the addition of TCEP abolished the protective effect of DDC against $\mathrm{A} \beta$-induced toxicity (Fig. 4B).

Increased Expression of HO-1 by DDC We investigated the involvement of the Nrf2-ARE pathway in the neuroprotective effect of DDC. Activation of the Nrf2-ARE pathway has been reported to cause the activation of HO-1. ${ }^{6,7)}$ Elevated expression of HO-1 has also been reported to exhibit a cytoprotective effect against oxidative stress in neurons. ${ }^{8)}$ Therefore, the influence of DDC on the expression level of HO-1 was examined. After $24 \mathrm{~h}$ of treatment with DDC $(30 \mu \mathrm{M})$, the expression of HO-1 was significantly elevated (Figs. 5A, B).

Effects of DDC via the Nrf2-ARE Pathway on A $\boldsymbol{\beta}$-Induced Neurotoxicity As shown in Fig. 5, DDC has been shown to activate the Nrf2-ARE pathway in cortical neurons. We therefore examined its effect on $\mathrm{A} \beta$-induced neuronal cell death. Since the expression level of HO-1 was increased $24 \mathrm{~h}$ after DDC treatment, we pretreated $\mathrm{A} \beta$ with DDC for $24 \mathrm{~h}$. However, DDC did not affect $\mathrm{A} \beta$-induced neuronal death under any of these conditions such as $24 \mathrm{~h}$ pretreatment of DDC (pre), $24 \mathrm{~h}$ pretreatment plus $48 \mathrm{~h}$ cotreatment (pre co), and $48 \mathrm{~h}$ cotreatment (co) (Fig. 6).

\section{DISCUSSION}

This study shows that DDC can protect against $\mathrm{A} \beta$-induced neurotoxicity in cerebral cortical neurons. We suggest that the 


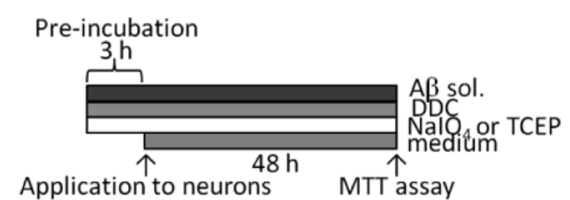

A

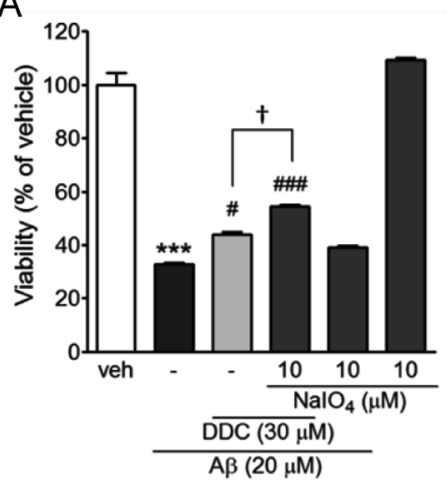

B

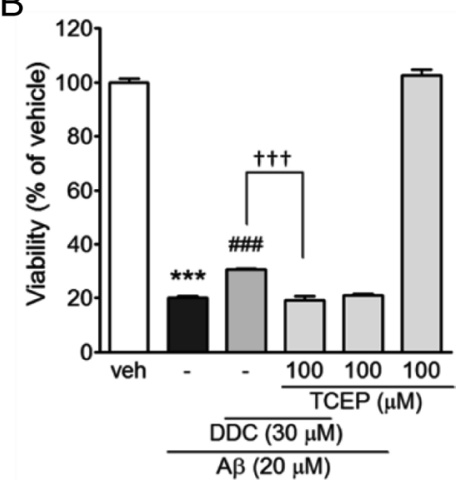

Fig. 4. Effects of $\mathrm{NaIO}_{4}$ or TCEP on the Neuroprotective Action of DDC

A, B: $\mathrm{A} \beta(20 \mu \mathrm{M})$ was preincubated for $3 \mathrm{~h}$ in the presence or absence of DDC $(30 \mu \mathrm{M})$ or $\mathrm{NaIO}_{4}(10 \mu \mathrm{M})(\mathrm{A})$ or TCEP $(100 \mu \mathrm{M})(\mathrm{B})$ at $37^{\circ} \mathrm{C}(\mathrm{pre}-\mathrm{incubation})$, and then added to Neurobasal medium. Cultures were treated for $48 \mathrm{~h}$ using the preincubated media. $* * * p<0.001$, compared with vehicle (veh), ${ }^{\#} p<0.05$, \#\#\# $p<0.001$, compared with $\mathrm{A} \beta,{ }^{\dagger} p<0.05,{ }^{\dagger \dagger} p<0.001$.

A

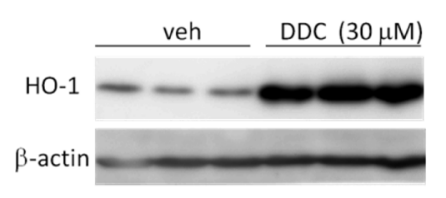

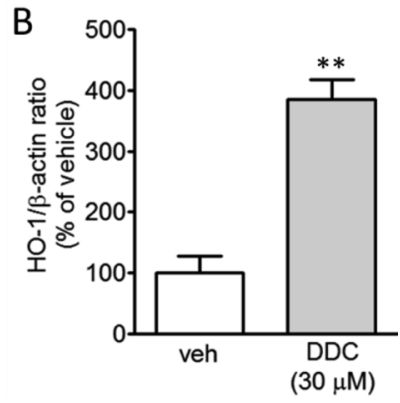

Fig. 5. Effect of DDC on HO-1 Expression in Cortical Neurons

A: Western blot image analysis. Cells were treated with DDC $(30 \mu \mathrm{M})$ for $24 \mathrm{~h}$ B: HO-1/ $\beta$-actin signal ratio was quantified and expressed as the fold of value of vehicle (veh). $* * p<0.01$, compared with veh.

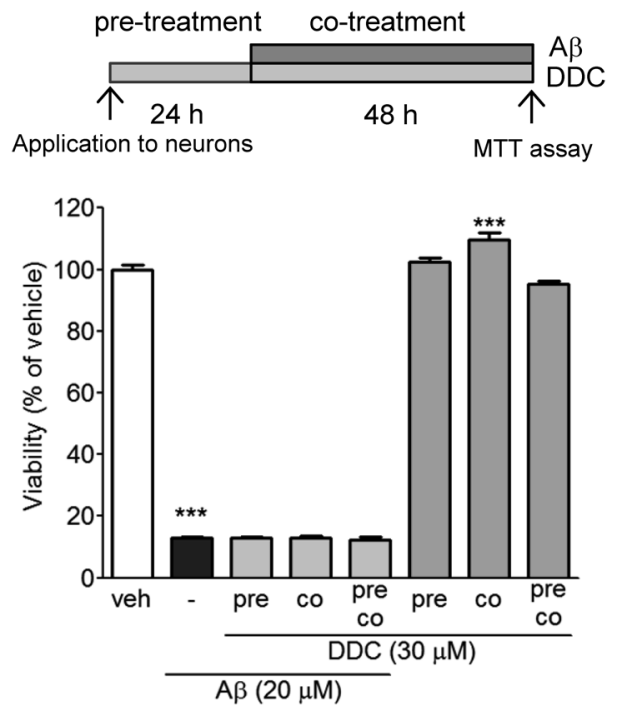

Fig. 6. Effect of DDC on $\mathrm{A} \beta$-Induced Neurotoxicity

Cultures were exposed to $\mathrm{A} \beta(20 \mu \mathrm{M})$ for $48 \mathrm{~h}$ with or without pretreatment for $24 \mathrm{~h}$ and co-treatment with DDC $(30 \mu \mathrm{M})$. ***p $<0.001$, compared with vehicle (veh). protective effect of DDC works through the suppression the aggregation of $\mathrm{A} \beta$.

Many naturally occurring polyphenols have been reported to contain a compound that has an aggregation inhibiting effect on $\mathrm{A} \beta$. $^{9)}$ Flavonoids, in particular, have a catechol group, and it was suggested that $o$-quinone form is formed by air oxidation of this catechol group, and that the aggregation of $\mathrm{A} \beta$ is suppressed by the formation of a covalent bond with basic amino acids on the $\mathrm{A} \beta$ peptide. ${ }^{4)}$ DDC has a catechol structure in its structure, and we showed here that it had an inhibitory effect on the aggregation of $\mathrm{A} \beta$ with this effect being enhanced by the oxidizing agent $\mathrm{NaIO}_{4}$ and attenuated by the reducing agent TCEP. Therefore, we consider that this effect of DDC also works via a similar mechanism of action. Further investigation such as a structural analysis will be necessary in future to fully understand the mechanism of action that leads to inhibition of the aggregation of $\mathrm{A} \beta$ by DDC.

Under conditions where $\mathrm{A} \beta$ and DDC were preincubated prior to addition to the cell culture, DDC showed an inhibitory effect against the aggregation of $\mathrm{A} \beta$ and neuroprotection against $\mathrm{A} \beta$-induced toxicity. However, under conditions where $\mathrm{A} \beta$ and DDC were simultaneously added to the media without a pre-incubation step, the aggregation was not prevented. No suppressive or neuroprotective effects were noted in the latter either. Although the exact reason to why this occurs will need further investigation, it is possible that the basal media used for the cell culture (Neurobasal medium) may contain a substance that interferes with the interaction between $\mathrm{A} \beta$ and DDC.

The aggregation of $\mathrm{A} \beta$ is known to increase the intracellular oxidative stress and that this is important for $\mathrm{A} \beta$-induced neurotoxicity. ${ }^{3)}$ In SH-SY5Y cells and PC12 cells, the activation of the Nrf2-ARE pathway suppressed $\mathrm{A} \beta$-mediated cytotoxicity. ${ }^{10,11)}$ In this study, the expression level of HO-1 was increased after $24 \mathrm{~h}$ of treatment with DDC, suggesting that DDC activates the Nrf2-ARE pathway in this cell culture system. However, when $\mathrm{A} \beta$ was treated under conditions that activated the Nrf2-ARE pathway (24h pretreatment with 
DDC), DDC was not able to suppress $\mathrm{A} \beta$-induced neurotoxicity (Fig. 6). The following possibility can be considered for the fact that DDC did not suppress $\mathrm{A} \beta$ toxicity despite activation of the Nrf2-ARE pathway. Antioxidant enzymes whose expression is elevated in neurons by DDC failed to eliminate reactive oxygen species produced by $\mathrm{A} \beta$ aggregates. Further investigation is needed to determine the detailed mechanism. Thus, in the present study, we showed that despite activation of the Nrf2-ARE pathway following treatment with DDC, the contribution of this pathway to the protective effect against $\mathrm{A} \beta$-induced neurotoxicity is small.

This study suggests that DDC exerts a protective action against $\mathrm{A} \beta$-induced neurotoxicity in the cerebral cortex by suppressing the aggregation of $\mathrm{A} \beta$. Targeting of $\mathrm{A} \beta$ has considerable interest for the treatment of AD. Since DDC has an inhibitory effect on the aggregation of $\mathrm{A} \beta$, DDC or DDC analogs may in future be useful for the prevention or in delaying the progression of $\mathrm{AD}$.

Acknowledgments This study was partially supported by a Grant from the Smoking Research Foundation.

Conflict of Interest The authors declare no conflict of interest.

\section{REFERENCES}

1) Jahn H. Memory loss in Alzheimer's disease. Dialogues Clin. Neurosci., 15, 445-454 (2013).

2) Fuentealba RA, Farias G, Scheu J, Bronfman M, Marzolo MP, Inestrosa NC. Signal transduction during amyloid-beta-peptide neurotoxicity: role in Alzheimer disease. Brain Res. Brain Res. Rev., 47,
275-289 (2004).

3) Izuo N, Kume T, Sato M, Murakami K, Irie K, Izumi Y, Akaike A. Toxicity in rat primary neurons through the cellular oxidative stress induced by the turn formation at positions 22 and 23 of $\mathrm{A} \beta 42 . A C S$ Chem. Neurosci., 3, 674-681 (2012).

4) Sato M, Murakami K, Uno M, Nakagawa Y, Katayama S, Akagi K, Masuda Y, Takegoshi K, Irie K. Site-specific inhibitory mechanism for amyloid $\beta 42$ aggregation by catechol-type flavonoids targeting the Lys residues. J. Biol. Chem., 288, 23212-23224 (2013).

5) Izumi Y, Matsumura A, Wakita $S$, Akagi K, Fukuda H, Kume T, Irie $\mathrm{K}$, Takada-Takatori $\mathrm{Y}$, Sugimoto $\mathrm{H}$, Hashimoto $\mathrm{T}$, Akaike A. Isolation, identification, and biological evaluation of Nrf2-ARE activator from the leaves of green perilla (Perilla frutescens var. crispa f. viridis). Free Radic. Biol. Med., 53, 669-679 (2012).

6) Myzak MC, Dashwood RH. Chemoprotection by sulforaphane: keep one eye beyond Keap1. Cancer Lett., 233, 208-218 (2006).

7) Morse D, Choi AM. Heme oxygenase-1: the "emerging molecule" has arrived. Am. J. Respir. Cell Mol. Biol., 27, 8-16 (2002).

8) Teng YC, Tai YI, Lee YH, Lin AM. Role of HO-1 in the arseniteinduced neurotoxicity in primary cultured cortical neurons. Mol. Neurobiol., 48, 281-287 (2013).

9) Churches QI, Caine J, Cavanagh K, Epa VC, Waddington L, Tranberg CE, Meyer AG, Varghese JN, Streltsov V, Duggan PJ. Naturally occurring polyphenolic inhibitors of amyloid beta aggregation. Bioorg. Med. Chem. Lett., 24, 3108-3112 (2014).

10) Lee C, Park GH, Lee SR, Jang JH. Attenuation of $\beta$-amyloidinduced oxidative cell death by sulforaphane via activation of NF-E2-related factor 2. Oxid. Med. Cell. Longev., 2013, 313510 (2013).

11) Li L, Du JK, Zou LY, Wu T, Lee YW, Kim YH. Decursin isolated from Angelica gigas Nakai rescues PC12 cells from amyloid-protein-induced neurotoxicity through Nrf2-mediated upregulation of heme oxygenase-1: optential roles of MAPK. Evid. Based Complement. Alternat. Med., 2013, 1-14 (2013). 